\title{
HUBUNGAN IMT PADA DM TIPE II DENGAN KEJADIAN DISFUNGSI SEKSUAL PADA WANITA USIA SUBUR (15-49 TAHUN) DI PUSKESMAS BROMO MEDAN
}

\author{
Melza Tatiana ${ }^{1}$, Heru Santosa ${ }^{2}$, Taufik Ashar ${ }^{3}$ \\ ${ }^{1}$ Mahasiswa Program Magister Ilmu Kesehatan Masyarakat, Universitas Sumatera Utara \\ Email: melzatatiana@gmail.com \\ ${ }^{2,3}$ Dosen Program Magister Ilmu Kesehatan Masyarakat, Universitas Sumatera Utara
}

\begin{abstract}
ABSTRAK
Diabetes mellitus (DM) merupakan salah satu penyakit kronis yang masih menjadi masalah utama dalam dunia kesehatan khususnya di Indonesia. Efek atau dampak yang di alami apabila seseorang terserang DM menimbulkann akibat sangat luas, salah satu nya kerugian yang dapat di alami oleh wanita yang terkena DM adalah gangguan kesehatan reproduksi. Wanita dengan DM cendrung mengalami gangguan seksual seperti terjadinya disfungsi seksual, disfungsi seksual pada wanita merupakan masalah kesehatan reproduksi yang penting karena berhubungan langsung dengan fungsi fisiologis reproduksi seorang wanita. Penelitian ini bertujuan untuk mengetahui hubungan IMT pada penderita diabetes mellitus tipe II dengan kejadian disfungsi seksual pada wanita usia subur di Puskesmas Bromo Medan. Penelitian ini adalah penelitian dengan pendekatan cross sectional. Penelitian ini menggunakan teknik purposive sampling dan memiliki 85 responden. Pada hasil penelitian, hasil uji statistic diperoleh p value sebesar 0,001. Berdasarkan kriteria uji Chi Square dapat dilihat bahwa p value $<$ a (a $<0,005)$, dengan demikian Ho ditolak dan Ha diterima, sehingga dapat diartikan bahwa IMT diabetes yang obesitas dapat mengakibatkan kejadian disfungsi seksual pada wanita di Puskesmas Bromo Medan. Hasil penelitian menunjukkan bahwa terdapat hubungan antara IMT DM tipe II dengan kejadiaan disfungsi seksual pada wanita usia subur. Hasil analisis diperoleh ( $p=<0,001 ; P R=2$ 95\% CI 1.185-15.045).
\end{abstract}

kata kunci : IMT, diabetes Mellitus tipe II, disfungsi seksual pada wanita.

\section{PENDAHULUAN}

\section{Latar Belakang}

Diabetes mellitus (DM) merupakan salah satu penyakit kronis yang masih menjadi masalah utama dalam dunia kesehatan khususnya di Indonesia. Prevalensi DM cukup tinggi di dunia. Diabetes Melitus tipe II adalah tipe diabetes yang paling banyak diderita dan terjadi pada sekitar 135 juta penduduk di seluruh dunia.

Efek atau dampak yang di alami apabila seseorang terserang DM. menimbulkann akibat sangat luas. Ada banyak kerugian yang akan di alami oleh penderita DM baik dari kerugian ekonomi, interaksi sosial, produktivitas jangka pendek dan produktivitas jangka panjang. Bukan hanya itu, kerugian yang akan di dapatkan juga melibatan kesehatan reproduksi, seperti disfungsi seksual, Disfungsi seksual merupakan kegagalan yang menetap atau berulang, baik sebagian atau secara keseluruhan,untuk memperoleh dan atau mempertahankan respon lubrikasi vasokongesti sampai berakhirnya aktifitas seksual(WHO, 2013).Wanita dengan DM cenderung mengalami faktorfaktor lain yang dapat memicu gangguan seksual seperti penelitian yang dilakukan oleh Ali (2008) di Yordania menyatakan bahwa prevalensi disfungsi seksual pada wanita dengan DM secara signifikan lebih tinggi dibandingkan dengan wanita tanpa DM. Wanita dengan DM memiliki gangguan minat, birahi, dan orgasme yang lebih banyak dibandingkan dengan wanita yang tidak DM.

Obesitas didefinisikan sebagai kelebihan berat badan. Indeks masa tubuh orang dewasa normalnya ialah antara 18,5 - $25 \mathrm{~kg} / \mathrm{m} 2$. Jika lebih dari $25 \mathrm{~kg} / \mathrm{m} 2$ maka dapat dikatakan seseorang tersebut mengalami obesitas (Gusti \& Erna, 2014)

Hasil pemantauan oleh Direktorat BGM (Bina Gizi Masyarakat) pada tahun 1996-1997 menunjukkan bahwa prevalensi kegemukan lebih banyak pada kelompok perempuan yakni 
sebesar 20\% sedangkan pada laki-laki sebesar12,8\% (Almatsier, 2006). Sebagaimana diketahui dalam berbagai penelitian, bahwa kegemukan atau obesitas merupakan faktor risiko kejadian DM tipe 2 yang cukup besar. Wanita yang memiliki Indeks Massa Tubuh yang sangat tinggi memiliki risiko lebih besar mengidap disfungsi seksual dibandingkan dengan wanita yang memiliki berat badan normal, karena ketidakseimbangan hormon yang disebabkan karena kelebihan lemak dalam tubuh. Ini menyebabkan globulin hormon seks lebih mengikat dalam sistem, yang mengikat testosteron (yang bertanggung jawab untuk gairah seksual), sehingga menghambat hasrat seksual normal.

\section{Rumusan Masalah}

Diabetes mellitus merupakan salah satu penyakit yang prevalensinya terus mengalami peningkatan di dunia. Jumlah kasus DM di wilayah kerja Puskesmas Bromo Medan 3 tahun terakhir mengalami peningkatan. DM diketahui menyebabkan komplikasi medis, salah satunya obesitas. Pada fungsi seksual wanita penderita diabetes baru baru ini diteliti dan menunjukkan bahwa wanita dengan diabetes juga mengalami peningkatan risiko untuk terjadinya disfungsi seksual. Berdasarkan hal tersebut maka yang menjadi permasalahan pada penelitian ini adalah apakah ada Hubungan IMT Diabetes Mellitus Tipe II Dengan Kejadian Disfungsi Seksual Pada Wanita Usia Subur Di Puskesmas Bromo Medan Tahun 2017?

Tujuan umum penelitian ini adalah untuk mengetahui Hubungan IMT Diabetes Mellitus Tipe II Dengan Kejadian Disfungsi Seksual Pada Wanita Usia Subur Di Puskesmas Bromo Medan Tahun 2017, manfaat penelitian ini di harapkan masyarakat khusus nya pasien DM yang obesitas agar lebih mewaspadai atau sedini mungkin mencegah komplikasi pada penyakit DM agar tidak mengalami kejadian disfungsi seksual, dan diharapkan menjadi masukan kepada para tenaga kesehatan untuk dapat meningkatkan perannya dalam mengurangi komplikasi pada pasien DM tipe 2 yang obesitas khususnya disfungsi seksual.

\section{METODE PENELITIAN}

\section{Jenis Penelitian}

Jenis penelitian ini menggunakan survei dengan rancangan crosssecsional. Penelitian cross secsional. Untuk mengetahui hubungan IMT diabates melitus tipe II dengan kejadian disfungsi seksual pada wanita usia subur di Puskesmas Bromo Medan tahun 2017. lokasi ini dipilih sebagai lokasi penelitian dengan pertimbangan karena penyakit DM merupakan urutan ke 3 dari 10 penyakit terbesar pada Laporan SP2TP, dan belum pernah di lakukan penelitian ini d Puskesmas Bromo Medan.

\section{Lokasi Penelitian}

Penelitian akan dilakukan di wilayah kerja Puskesmas Bromo Medan.

\section{Populasi dan Sampel Penelitian \\ Populasi Penelitian}

Populasi yang berjumlah 158 orang

\section{Sampel Penelitian}

Sampel adalah sebagian dari populasi yang diambil berdasarkan teknik tertentu dan mampu mewakili populasi atau bersifat representatif atau mewakili dari seluruh populasi. Perhitungan besar sampel ditentukan dengan menggunakan rumus untuk uji hipotesis proporsi sampel tunggal (Lemeshow, 1997), sebagai berikut : 


$$
n=\frac{\left\{Z_{1-\alpha / 2} \sqrt{P_{O}}\left(1-P_{O}\right)+Z_{1-\beta} \sqrt{P_{a}}\left(1-P_{a}\right)\right\}^{2}}{\left(P_{a}-P_{O}\right)^{2}}
$$

maka :

$$
\begin{gathered}
n=\frac{\{1.96 \sqrt{0,5}(1-0,5) 0,8742 \sqrt{0,35}(1-0,5)\}^{2}}{(0,5-0,35)^{2}} \\
n=84,83 \approx 85
\end{gathered}
$$

\section{Tekhnik Pengambilan Sampel}

Teknik pengambilan sampel dengan cara purposive sampling

\section{Metode Pengumpulan Data}

Data Primer

Data primer diperoleh melalui penyebaran daftar pernyataan berupa kuesioner yang di bagikan kepada wanita yang mengalami DM tipe II

\section{Data Sekunder}

Data Sekunder dalam penelitian ini adalah berupa laporan / dokumentasi yang di peroleh dari Puskesmas Bromo Medan, yaitu data - data mengenai jumlah wanita usia subur yang menderita DM tipe II.

\section{Metode Analisa Data}

\section{Analisis Univariat (univariate analysis)}

Analisis univariat dilakukan untuk mendapatkan gambaran karakteristik responden dan distribusi frekuensi variabel independen dan dependen

\section{Analisis Bivariat (bivariate analysis)}

Analisis bivariat digunakan untuk mendapatkan informasi tentang hubungan variabel independen yaitu IMT , dengan variabel dependen (disfungsi seksual) dengan menggunakan Uji Chi Square dan menggunakan derajat kemaknaan $\alpha=0,05$. Bila nilai $p<0,05$ maka hasil statistik dikatakan berhubungan.

\section{Metode Pengukuran}

\section{Pengukuran Variabel Dependen}

Pengukuran variable dependen yaitu disfungsi seksual pada wanita yang menderita DM tipe 2 dinilai melalui kuesioner FSFI. Kuesioner FSFI memiliki beberapa domain dan terdiri dari 19 pertanyaan. Satu domain berisikan 2 pertanyaan atau lebih. Untuk menilai skor domain individu, pada pertanyaan masing-masing domain jumlahkan skor yang didapat lalu kalikan jumlah tersebut dengan faktor domain. Tambahkan nilai keenam domain untuk mendapatkan skala penuh. Perlu dicatat bahwa pada rentang skor yang menunjukkan angka nol berarti bahwa subjek yang dilaporkan tidak memiliki aktivitas seksual dalam sebulan terakhir. Skor subjek penelitian lalu dapat dimasukkan dalam kolom sebelah kanan. 
Tabel 1. Skor Penilaian FSFI

\begin{tabular}{cccccccc}
\hline No & Doamain & Pertanyaan & $\begin{array}{c}\text { Rentang } \\
\text { skor }\end{array}$ & faktor & $\begin{array}{c}\text { Skor } \\
\text { min }\end{array}$ & $\begin{array}{c}\text { Skor } \\
\text { max }\end{array}$ & skor \\
\hline 1 & Hasrat seksual & 1,2 & $1-5$ & 0,6 & 1,2 & 6 & \\
2 & $\begin{array}{c}\text { Rangsangan } \\
\text { seksual }\end{array}$ & $3,4,5,6$ & $0-5$ & 0,3 & 0 & 6 \\
3 & $\begin{array}{c}\text { Lubrikasi } \\
\text { Vagian }\end{array}$ & $7,8,9,10$ & $0-5$ & 0,3 & 0 & 6 \\
& & & & & \\
5 & orgasme & $11,12,13$ & $0-5$ & 0,4 & 0 & 6 \\
5 & kepuasan & $14,15,16$ & $0-5$ & 0,4 & 0 & 6 \\
\hline
\end{tabular}

\section{Pengukuran Variabel inpenden}

Mengukur langsung pada responden tinggi badan diukur dengan meteran (bath room scale) sedangkan berat badan menggunakan timbangan injak, cara ukur, obesitas jika IMT $>25 \mathrm{~kg} / \mathrm{m}^{2}$ tidak obesitas jika $\mathrm{IMT} \leq 25 \mathrm{~kg} / \mathrm{m}^{2}$ (depkes, 2005).

\section{HASIL DAN PEMBAHASAN}

Tabel 2. Distribusi Frekuensi IMT Wanita Subur di Wilayah Kerja Puskesmas Bromo Medan Tahun 2017

\begin{tabular}{cccc}
\hline No & IMT & Frekuensi & \% \\
\hline 1 & Obesitas $\left(\mathrm{IMT}>25 \mathrm{~kg} / \mathrm{m}^{2}\right)$ & 52 & 61.2 \\
\hline 2 & Tidak obesitas $\left(\mathrm{IMT} \leq 25 \mathrm{~kg} / \mathrm{m}^{2}\right)$ & 33 & 38.8 \\
\hline & Jumlah & $\mathbf{8 5}$ & $\mathbf{1 0 0 , 0}$ \\
\hline
\end{tabular}

IMT wanita usia subur mayoritas obesitas sebanyak 52 orang $(61,2 \%)$

Tabel 3. Hubungan IMT, Dengan Disfungsi Seksual Pada Wanita Usia Subur Pada Wanita Usia Subur

\begin{tabular}{|c|c|c|c|c|c|c|c|c|}
\hline \multirow{3}{*}{$\begin{array}{c}\text { Variabel } \\
\text { Independen }\end{array}$} & \multicolumn{4}{|c|}{ Disfungsi Seksual } & \multirow{2}{*}{\multicolumn{2}{|c|}{ Total }} & \multirow{3}{*}{$\begin{array}{c}p \\
\text { value }\end{array}$} & \multirow{3}{*}{$\begin{array}{c}\text { PR } \\
95 \% \mathrm{CI}\end{array}$} \\
\hline & \multicolumn{2}{|c|}{ Disfungsi } & \multicolumn{2}{|c|}{$\begin{array}{c}\text { Tidak } \\
\text { Disfungsi }\end{array}$} & & & & \\
\hline & $\mathbf{n}$ & $\%$ & $\mathbf{n}$ & $\%$ & n & $\%$ & & \\
\hline IMT & & & & & & & & \\
\hline$>25 \mathrm{~kg} / \mathrm{m}^{2}$ & 42 & 77.8 & 8 & 25.8 & 50 & 61.2 & $<0,001$ & $\begin{array}{c}2 \\
185 \times 15045\end{array}$ \\
\hline$\leq 25 \mathrm{~kg} / \mathrm{m}^{2}$ & 12 & 22.2 & 23 & 74.2 & 35 & 38.8 & & $1.185-15.045$ \\
\hline
\end{tabular}

Bahwa dari 50 orang wanita usia subur yang mengalami obesitas terdapat 42 orang $(77,8 \%)$ yang mengalami disfungsi seksual dan 8 orang $(25,8 \%)$ yang tidak disfungsi seksual . Sedangkan dari 35 orang wanita usia subur yang tidak obesitas terdapat 12 orang $(22,2 \%)$ yang mengalami disfungsi seksual dan 23 orang (74,2\%) yang tidak disfungsi seksual. Hasil uji statistik diperoleh nilai $\mathrm{p}=0,001$ artinya bahwa ada pengaruh IMT terhadap disfungsi seksual pada wanita usia subur. Dari hasil analisis juga diperoleh nilai PR $=2$ 95\%CI 1.185-15.045) artinya bahwa wanita usia subur yang mengalami obesitas memiliki peluang berisiko 2 kali lebih besar mengalami disfungsi seksual dibanding dengan yang tidak obesitas. 
Indeks Massa Tubuh merupakan salah satu faktor yang dapat mempengaruhi disfungsi seksual pada wanita yang menderita diabetes melitus tipe II, secara statistik hasil penelitian ini menyatakan bahwa ada hubungan yang signifikan antara IMT dengan kejadian disfungsi seksual pada wanita yang menderita diabetes melitus tipe II di Puskesmas Bromo Medan.

Hasil penelitian ini sejalan dengan penelitian yang dilakukan oleh Saraswati menyatakan bahwa wanita yang memiliki Indeks Massa Tubuh yang sangat tinggi memiliki risiko lebih besar mengidap disfungsi seksual dibandingkan dengan wanita yang memiliki berat badan normal.

Pada penelitian Esposito yang meneliti hubungan antara Obesitas dengan fungsi seksual pada wanita yang menggunakan FSFI score, dijumpai bahwa adanya hubungan yang terbalik antara BMI dengan FSFI score. Dimana BMI yang tinggi dijumpai FSFI score yang rendah. Yang artinya pada wanita obesitas nilainya menunjukkan disfungsi seksual . Bila dihubungkan dengan ke enam domain yang ada di FSFI score tersebut ( keinginan, gairah, lubrikasi, orgasme,kepuasan, nyeri ), dengan BMI, maka dijumpai BMI yang tinggi akan memiliki keinginan, gairah, lubrikasi dan orgasme yang rendah.

Hasil ini juga sesuai dengan teori bahwa terjadi penurunan fungsi seksual seiring dengan meningkatnya nilai Indeks karena perubahan hormonal dalam tubuh seseorang dengan obesitas. Karena estrogen dan androgen menjadi salah satu faktor yang memengaruhi fungsi seksual pada wanita, terjadinya penurunan kedua hormon tersebut pada orang obesitas dapat menyebabkan penurunan fungsi seksual. obesitas pada wanita juga menghadapi bagian dari masalah yang berhubungan dengan seks. Alasannya adalah ketidak seimbangan hormon yang disebabkan karena kelebihan lemak dalam tubuh. Ini menyebabkan globulin hormon seks lebih mengikat dalam sistem, (yang bertanggung jawab untuk gairah seksual), sehingga menghambat hasrat seksual normal.

\section{KESIMPULAN DAN SARAN}

\section{Kesimpulan}

Ada hubungan IMT dengan kejadian disfungsi seksual pada wanita usia subur di Puskesmas Bromo Medan Tahun 2017

\section{Saran}

Bagi puskesmas agar menjadi masukan kepada para tenaga kesehatan untuk dapat meningkatkan perannya dalam mengurangi komplikasi pada pasien obesitas yang menderita DM tipe 2 khususnya disfungsi seksual.

Melakukan penyuluhan pada wanita usia subur tentang komplikasi yang terjadi pada penderita diabates mellitus dan bagi kesehatan, dan juga melibatkan keluarga terdekat agar lebih menekankan mereka untuk selalu rutin memriksakan diri ke puskesmas dan menghindari faktor risiko yang dapat meningkatkan gula dalam darah.

Bagi masyarakat khusus nya pasien DM agar lebih mewaspadai atau sedini mungkin mencegah komplikasi pada penyakit DM agar tidak mengalami kejadian disfungsi seksual. 


\section{REFERENSI}

Ali RMA, Hajeri RMA, Khader YS, Shegem NS, Ajlouni KM, 2008. Sexual Dysfunction In Jordanian Diabetic Women. Diabetes Care;31:1580-1.

Almatsier, Sunita, 2006. Prinsip Dasar Ilmu Gizi. Jakarta: PT Gramedia Pustaka Umat.

Departemen Kesehatan RI, 2003. Petunjuk Teknis Pemantauan Status Gizi Orang Dewasa dengan Indeks Massa Tubuh (IMT), Jakarta; [internet] 2003. [cited 14 Desember 2013] Available from:http://www.depkes.go.id/index.php.vw=2\&id=A-137

Esposito, K. et al., 2010. Determinants Of Female Sexual Dysfunction In Type 2 Diabetes. International Journal Of Impotence Research, 22(3), pp.179-184. Available at: http://dx.doi.org/10.1038/ijir.2010.6.

Gusti, Erna, 2014 . Hubungan Faktor Risiko Usia, Jenis Kelamin, Kegemukan dan Hipertensi dengan Kejadian Diabetes Mellitus Tipe 2 di Wilayah Kerja Puskesmas Mataram. Media Bina Ilmiah . Volume 8. No.1 : $39-44$

Saraswati, M.R, 2011. Disfungsi Seksual pada Wanita Penderita Diabetes Melitus Tipe 2. J Peny Dalam, 12, pp.92-97.

WHO, 2013. Obesity and Overweight. Available from: http://www.who.int/diakses pada tanggal 13 April 2017. 